\title{
Periprocedural Predictors of New-Onset Conduction Abnormalities After Transcatheter Aortic Valve Replacement
}

\author{
Kensuke Matsushita, MD; Mohamad Kanso, MD; Mickael Ohana, MD, PhD; \\ Benjamin Marchandot, MD; Marion Kibler, MD; Joe Heger, MD; Marilou Peillex, MD; \\ Antonin Trimaille, MD; Sébastien Hess, MD; Lelia Grunebaum, MD; Antje Reydel, MD; \\ Fabien De Poli, MD; Pierre Leddet, MD; Jérôme Rischner, MD; Philoktemon Plastaras, MD; \\ Laurence Jesel, MD, PhD; Olivier Morel, MD, PhD; Patrick Ohlmann, MD, PhD
}

\begin{abstract}
Background: New-onset conduction abnormalities (CAs) following transcatheter aortic valve replacement (TAVR) are associated with hospital rehospitalization and long-term mortality, but available predictors are sparse. This study sought to determine clinical predictors of new-onset left bundle branch block (LBBB) and new permanent pacemaker (PPM) implantation in patients undergoing TAVR.

Methods and Results: We enrolled 290 patients who received SAPIEN 3 (Edwards Lifesciences, Irvine, CA, USA; $n=217$ ) or Evolut R (Medtronic, Minneapolis, MN, USA; $n=73$ ) from a prospective registry at Nouvel Hôpital Civil, Strasbourg, France between September 2014 and February 2018. Of 242 patients without pre-existing LBBB, 114 (47\%) experienced new-onset LBBB and/or new PPM implantation. A difference between membranous septal length and implantation depth ( $\triangle M S I D)$ was the only predictor of CAs for both types of valves. In the multivariate analysis, PR interval and $\triangle M S I D$ remained as sole predictors of CAs. The risk for adverse clinical events, including all-cause death, myocardial infarction, stroke, and heart failure hospitalization, was higher for patients with CAs as compared with patients without CAs (hazard ratio: 2.10 ; 95\% confidence interval: 1.26 to $3.57 ; P=0.004$ ).
\end{abstract}

Conclusions: Computed tomography assessment of membranous septal anatomy and implantation depth predicted CAs after TAVR with new-generation valves. Future studies are required to identify whether adjustment of the implantation depth can reduce the risk of CAs and adverse clinical outcomes.

Key Words: Implantation depth; Left bundle branch block; Membranous septum; Pacemakers; Transcatheter aortic valve replacement

$\mathbf{T}$ ranscatheter aortic valve replacement (TAVR) is an established therapeutic option for intermediate and high surgical risk patients with severe aortic stenosis (AS). ${ }^{1-3}$ Despite increased operator experience and updated valve technologies, cardiac conduction abnormalities (CAs) remain a frequent TAVR complication. ${ }^{46}$ Clinically relevant CAs after TAVR include high-degree atrioventricular block (AVB) and other arrhythmias requiring permanent pacemaker (PPM) implantation, and new-onset left branch bundle block (LBBB). ${ }^{5,7}$ The incidence of these remains frequent after TAVR, seen in $31-45 \%$ of patients depending on the type of valve implanted., 4,7 Recent studies have suggested that not only new PPM implantation, but also new-onset LBBB could be associated with repeat rehospi- talization and increased mortality.,9,10

Pre-existing right bundle branch block (RBBB), firstdegree AVB, self-expandable valves, intraoperative AVB, implantation depth (ID), and the length of the membranous septum (MS) have been identified as predictors of CAs. ${ }^{10-14}$ However, the majority of studies have been restricted to earlier-generation prostheses and the definitions of CAs have been limited to new PPM implantation. The present study was therefore designed to delineate the predictive factors of new-onset LBBB and new PPM implantation after TAVR with new-generation valves. Our main objective was to establish correlations between periprocedural imaging and clinical data and CAs.

Received March 25, 2020; revised manuscript received June 10, 2020; accepted June 22, 2020; J-STAGE Advance Publication released online September 1, 2020 Time for primary review: 29 days

Université de Strasbourg, Pôle d'Activité Médico-Chirurgicale Cardio-Vasculaire (K.M., M. Kanso, B.M., M. Kibler, J.H., M.P., A.T., S.H., A.R., L.J., O.M., P.O.), Department of Radiology (M.O.), Department of Haemostasis (L.G.), Nouvel Hôpital Civil, Centre Hospitalier Universitaire, Strasbourg; UMR1260 INSERM, Nanomédecine Régénérative, Faculté de Pharmacie, Université de Strasbourg, Illkirch (K.M., O.M.); Department of Cardiology, Centre Hospitalier de Haguenau, Haguenau (F.D.P., P.L.); and Department of Cardiology, Centre Hospitalier Schweitzer, Colmar (J.R., P.P.), France

Mailing address: Patrick Ohlmann, MD, PhD, Pôle d'Activité Médico-Chirurgicale Cardio-Vasculaire, Nouvel Hôpital Civil, Centre Hospitalier Universitaire, 1 place de l'Hôpital - 67091 Strasbourg cedex, France. E-mail: Patrick.Ohlmann@chru-strasbourg.fr

All rights are reserved to the Japanese Circulation Society. For permissions, please e-mail: cj@j-circ.or.jp

ISSN-1346-9843 


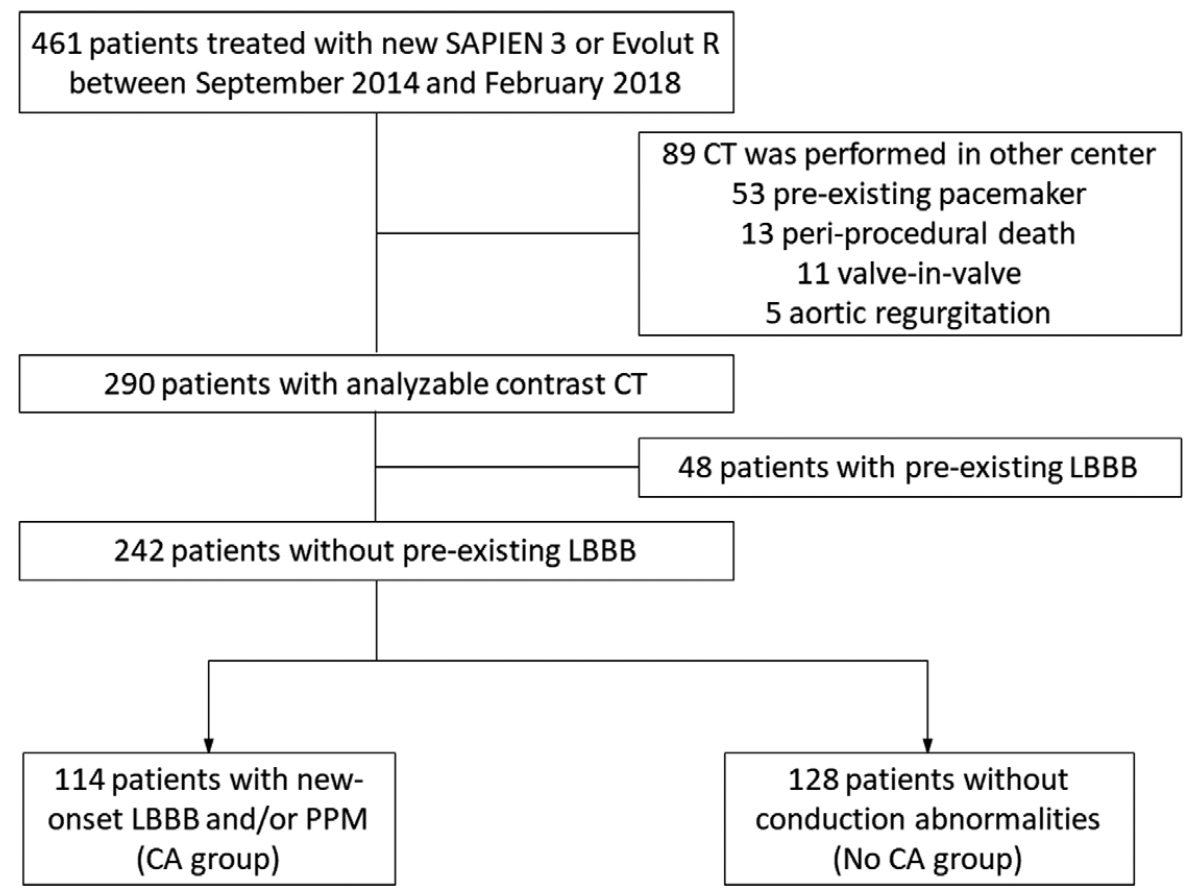

Figure 1. Study flowchart. CA, conduction abnormality; CT, computed tomography; LBBB, left bundle branch block; PPM, permanent pacemaker.

\section{Methods}

\section{Study Design and Population}

A total of 290 patients undergoing TAVR were enrolled from a prospective registry at Nouvel Hôpital Civil, Université de Strasbourg, Strasbourg, France, between September 2014 and February 2018. The patient flow through the study is shown in Figure 1. All patients had symptomatic severe AS and intermediate to high perioperative risks of death, as assessed by the logistic EuroSCORE. The indication for TAVR and approach were assessed by the local heart team. All participants gave informed written consent before the procedure and agreed to anonymous processing of their data (France 2 and France TAVI registries). The present study was performed according to the Declaration of Helsinki. Patients received aspirin $(75-160 \mathrm{mg}$ ) and clopidogrel (300 mg loading dose and $75 \mathrm{mg} /$ day maintenance dose) before TAVR, with ongoing dual antiplatelet therapy for 3 months after the procedure.

\section{Data Source}

Baseline characteristics of the enrolled patients were collected prospectively. Pre- and postprocedural ECGs were validated in all patients. RBBB and LBBB were defined by appropriate society guidelines. ${ }^{15} \mathrm{CAs}$ were defined as newonset LBBB and/or new PPM implantation during hospitalization.

\section{Study Devices and Procedures}

For TAVR, the balloon-expandable SAPIEN 3 prosthesis (Edwards Lifesciences, Irvine, CA, USA) or the self-expandable Evolut R (Medtronic, Minneapolis, MN, USA) was used. During the procedure, $100 \mathrm{IU} / \mathrm{kg}$ of unfractionated heparin was administered to achieve an activated clotting time of $250-350 \mathrm{~s}$. At the end of the procedure, heparin was antagonized with $100 \mathrm{IU} / \mathrm{kg}$ of protamine.

\section{Computed Tomography Acquisition}

Preprocedural ECG-gated multidetector computed tomography (CT) examinations using a 2nd or 3rd-generation 320row CT scanners (Aquilion ONE Vision Edition, Aquilion One Genesis, Canon Medical Systems, Japan) were performed. The aortic root CT was acquired in volume mode using a retrospective ECG-gated acquisition and the following CT parameters: $16 \mathrm{~cm}$ width, $100 \mathrm{kV}$, gantry rotation time of $0.275 \mathrm{~s}$, auto-mA maxed at 300 , acquisition over 1 heartbeat. ${ }^{16}$ Acquisition was obtained after a bolus injection of $50-70 \mathrm{~mL}$ of iomeprol $400 \mathrm{mg} / \mathrm{mL}$ (Iomeron ${ }^{\circledR}$, Bracco, Italy), using an automatic power injector at a rate of $3.5 \mathrm{~mL} / \mathrm{s}$, followed by a $30-\mathrm{mL}$ saline chaser at a rate of $3 \mathrm{~mL} / \mathrm{s}$. The acquisition was triggered using a bolus-tracking technique with the region of interest positioned in the descending thoracic aorta and a 180 Hounsfield units threshold.

\section{Aortic Valve Calcium Scoring}

Aortic valve calcium score measurements were performed off-line on a dedicated workstation using Vitrea software in version 6.6 (Vital Imaging, USA) by the Agaston method ${ }^{17}$ and expressed in arbitrary units (AU). All scorings were performed by the same operator (K.M., cardiologist with 2 years of experience in $\mathrm{CT}$ ).

\section{Depth of Valves and MS Length}

The depth of bioprosthesis implantation in the left ventricular outflow track was measured using a final fluoroscopic aortic angiographic acquisition after valve implantation. 


\begin{tabular}{|c|c|c|c|}
\hline & CA $(n=114)$ & No CA $(n=128)$ & $P$ value \\
\hline Age, years & $84.1 \pm 7.1$ & $83.8 \pm 7.0$ & 0.71 \\
\hline Male & 45 (39) & 49 (38) & 0.85 \\
\hline Body mass index, $\mathrm{kg} / \mathrm{m}^{2}$ & $27.7 \pm 6.2$ & $26.8 \pm 5.7$ & 0.25 \\
\hline Hypertension & $94(82)$ & $112(88)$ & 0.27 \\
\hline Diabetes mellitus & $35(31)$ & $38(30)$ & 0.86 \\
\hline Dyslipidemia & $66(58)$ & $69(54)$ & 0.53 \\
\hline CKD & $56(49)$ & $45(35)$ & 0.03 \\
\hline COPD & $21(18)$ & $21(16)$ & 0.68 \\
\hline Cerebrovascular disease & $12(11)$ & $20(16)$ & 0.24 \\
\hline Ischemic heart disease & $44(39)$ & $64(50)$ & 0.07 \\
\hline AF history & $40(35)$ & $36(28)$ & 0.24 \\
\hline PR interval, ms & $199 \pm 44$ & $177 \pm 30$ & $<0.001$ \\
\hline Presence of RBBB & $19(17)$ & $16(13)$ & 0.36 \\
\hline Presence of LBBB & - & - & - \\
\hline Duration of QRS, ms & $122 \pm 44$ & $115 \pm 34$ & 0.21 \\
\hline Logistic EuroSCORE & $18.9 \pm 11.7$ & $19.0 \pm 13.3$ & 0.98 \\
\hline \multicolumn{4}{|l|}{ Echocardiographic data } \\
\hline Mean aortic gradient, $\mathrm{mmHg}$ & $50 \pm 13$ & $49 \pm 13$ & 0.64 \\
\hline Aortic valve area, $\mathrm{mm}^{2}$ & $0.73 \pm 0.22$ & $0.74 \pm 0.19$ & 0.98 \\
\hline LVEF, \% & $56 \pm 12$ & $57 \pm 12$ & 0.63 \\
\hline $\mathrm{sPAP}, \mathrm{mmHg}$ & $40 \pm 13$ & $40 \pm 14$ & 0.76 \\
\hline \multicolumn{4}{|l|}{ CT data } \\
\hline Annulus area, $\mathrm{mm}^{2}$ & $456 \pm 90$ & $442 \pm 93$ & 0.30 \\
\hline MS length, $\mathrm{mm}$ & $7.5 \pm 2.9$ & $8.4 \pm 2.4$ & 0.01 \\
\hline Calcification in basal septum & $42(37)$ & $44(34)$ & 0.69 \\
\hline $\mathrm{AV}$ calcium score, $\mathrm{AU}$ & $3,131(2,230-4,308)$ & $3,004(2,209-3,983)$ & 0.26 \\
\hline MV calcium score, $\mathrm{AU}$ & $820(95-3,920)$ & $751(124-2,664)$ & 0.50 \\
\hline Type of valve & & & 0.26 \\
\hline SAPIEN 3 & $81(71)$ & $99(77)$ & \\
\hline Evolut $\mathrm{R}$ & $33(29)$ & $29(23)$ & \\
\hline Diameter of valve (mm) & & & 0.02 \\
\hline 23 & $31(27)$ & $53(41)$ & \\
\hline 26 & $43(38)$ & $50(39)$ & \\
\hline 29 & $39(34)$ & $25(20)$ & \\
\hline 34 & $1(1)$ & $0(0)$ & \\
\hline Procedure time, $\min$ & $79 \pm 20$ & $79 \pm 25$ & 0.94 \\
\hline Predilatation & $73(64)$ & $68(53)$ & 0.09 \\
\hline Postdilatation & $5(4)$ & $11(9)$ & 0.19 \\
\hline Implantation depth (NCC), mm & $6.2 \pm 2.2$ & $5.8 \pm 2.9$ & 0.21 \\
\hline Implantation depth (LCC), mm & $5.3 \pm 2.7$ & $4.5 \pm 2.4$ & 0.02 \\
\hline Implantation depth (mean), mm & $5.7 \pm 2.3$ & $5.1 \pm 1.9$ & 0.03 \\
\hline$\Delta \mathrm{MSID}, \mathrm{mm}$ & $1.8 \pm 3.1$ & $3.4 \pm 3.0$ & $<0.001$ \\
\hline
\end{tabular}

Values are $n(\%)$, mean $\pm S D$, or median (interquartile range). AF, atrial fibrillation; $A U$, Agatston units; $A V$, aortic valve; CKD, chronic kidney disease; COPD, chronic obstructive pulmonary disease; CT, computed tomography; LBBB, left bundle branch block; LCC, left coronary cusp; LVEF, left ventricular ejection fraction; MS, membranous septum; MV, mitral valve; NCC, noncoronary cusp; sPAP, systolic pulmonary artery pressure; RBBB, right bundle branch block; $\triangle \mathrm{MSID}$, difference between length of MS and implantation depth.

The ID was defined as the average distance from the native aortic annulus plane (on the side of the noncoronary cusp and on the side of the left coronary cusp) to the proximal edge of the implanted valve (deepest level in the left ventricle). MS length was determined on the preprocedure CT, during systole, using the coronal view as previously described. ${ }^{13}$ In addition, the difference between MS length and mean ID was calculated to define the difference between them ( $\triangle$ MSID).

\section{Prosthesis Oversizing}

Oversizing was calculated as follows: oversizing by area $(\%)=($ valve area/annulus area -1$) \times 100$ for SAPIEN 3; oversizing by perimeter $(\%)=($ valve perimeter/annulus perimeter-1) $\times 100$ for Evolut R. ${ }^{12,18}$ The nominal area of a fully expanded SAPIEN 3 is $409 \mathrm{~cm}^{2}$ for the $23-\mathrm{mm}$ valve, $519 \mathrm{~mm}^{2}$ for the $26-\mathrm{mm}$ valve, and $649 \mathrm{~mm}^{2}$ for the $29-\mathrm{mm}$ valve. In contrast, the nominal perimeter of a fully expanded Evolut $\mathrm{R}$ is $72.22 \mathrm{~mm}$ for the $23-\mathrm{mm}$ valve, 

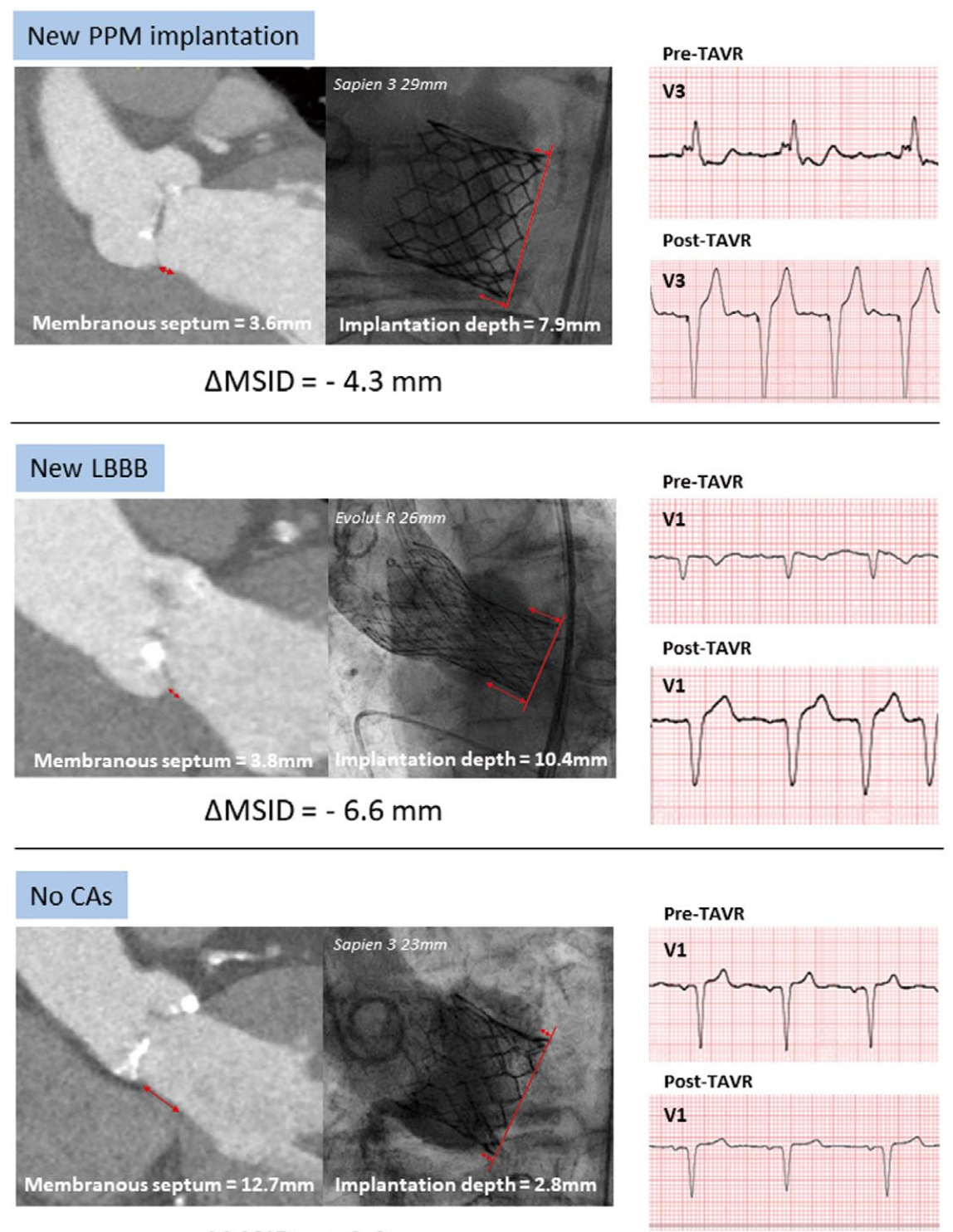

$$
\Delta \mathrm{MSID}=+9.9 \mathrm{~mm}
$$

Figure 2. Representative cases of CAs following TAVR. CAs, conduction abnormalities; LBBB, left bundle branch block; PPM, permanent pacemaker; TAVR, transcatheter aortic valve replacement; $\Delta \mathrm{MSID}$, difference between length of membranous septum and implantation depth.

$81.64 \mathrm{~mm}$ for the $26-\mathrm{mm}$ valve, $91.06 \mathrm{~mm}$ for the $29-\mathrm{mm}$ valve, and $106.76 \mathrm{~mm}$ for the $34-\mathrm{mm}$ valve.

\section{Definition of Major Adverse Cardiovascular Events (MACEs)}

MACE was defined as a composite of all-cause death, myocardial infarction, stroke, and heart failure hospitalization. Outcome data were collected by serial contact with the patients and from their medical records.

\section{Statistical Analysis}

Categorical variables are expressed as numbers (\%), and continuous variables are expressed as mean $\pm \mathrm{SD}$ or median and interquartile values. Differences between 2 groups were assessed with $\chi^{2}$ tests for categorical variables. Unpaired Student's t-test was used to analyze continuous variables that showed normal distributions, and the Wilcoxon test was used to analyze continuous variables with skewed distributions. Univariate and multivariate logistic regression analyses were performed to identify independent predictors of CAs. Variables with $\mathrm{P}$ value $<0.1$ in the univariate analysis were included in the multivariate analyses. Event rates over time were summarized using Kaplan-Meier estimates, and log-rank tests were used to perform comparisons between patients with and without CAs. $\mathrm{P}$ values of $<0.05$ were considered to indicate statistical significance. All analyses were performed using JMP 13 software $^{\circledR}$ (SAS Institute, Cary, NC, USA). 
A

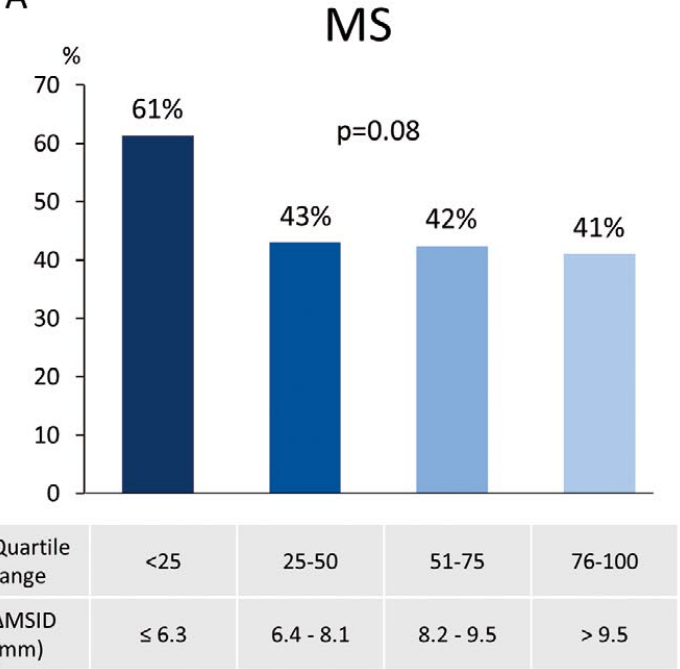

B

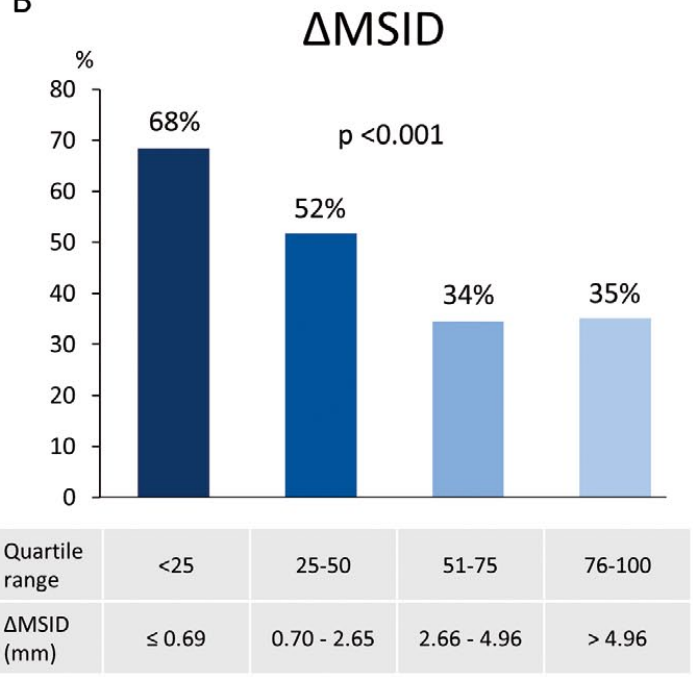

Figure 3. Percentage of conduction abnormalities by quartile of MS length (A) and $\triangle M S I D(B)$. MS, membranous septum; $\Delta M S I D$, difference between length of MS and implantation depth.

\section{Results}

\section{Patients' Characteristics}

Of the 290 patients analyzed, 48 had pre-existing LBBB. CAs were evidenced in 114 of the remaining 242 patients (47\%) (Figure 1). Baseline clinical and procedural characteristics for the patients with new-onset CAs showed higher incidence of chronic kidney disease (CKD) (49\% vs. 35\%, $\mathrm{P}=0.03)$ and longer $\mathrm{PR}$ interval $(199 \pm 44 \mathrm{~ms}$ vs. $177 \pm 30 \mathrm{~ms}$, $\mathrm{P}<0.001$ ) (Table 1). Patients with new-onset LBBB had higher incidence of CKD ( $52 \%$ vs. $36 \%, \mathrm{P}=0.02)$ and longer PR interval $(197 \pm 42 \mathrm{~ms}$ vs. $180 \pm 35 \mathrm{~ms}, \mathrm{P}=0.003)$. Patients requiring PPM had higher body mass index $\left(28.5 \pm 6.1 \mathrm{~kg} / \mathrm{m}^{2}\right.$ vs. $26.7 \pm 5.9 \mathrm{~kg} / \mathrm{m}^{2}, \mathrm{P}=0.03$ ), higher incidence of chronic pulmonary occlusive disease $(28 \%$ vs. $15 \%, \mathrm{P}=0.02)$ and pre-existing RBBB ( $30 \%$ vs. $7 \%, \mathrm{P}<0.001)$, longer $\mathrm{PR}$ interval $(201 \pm 43 \mathrm{~ms}$ vs. $186 \pm 37 \mathrm{~ms}, \mathrm{P}=0.02)$ and $\mathrm{QRS}$ duration $(136 \pm 40 \mathrm{~ms}$ vs. $120 \pm 37 \mathrm{~ms}, \mathrm{P}=0.006)$.

\section{CT Measurements and Implantation Depth}

Patients who presented with new CAs had a significantly shorter MS (7.5 $\pm 2.9 \mathrm{~mm}$ vs. $8.4 \pm 2.4 \mathrm{~mm}, \mathrm{P}=0.01)$ and lower implantation depth $(5.7 \pm 2.3 \mathrm{~mm}$ vs. $5.1 \pm 1.9 \mathrm{~mm}$, $\mathrm{P}=0.03$ ) than patients without CAs (Table 1). $\triangle$ MSID was smaller in patients with CAs after TAVR $(1.8 \pm 3.1 \mathrm{~mm}$ vs. $3.4 \pm 3.0 \mathrm{~mm}, \mathrm{P}<0.001)$. There was no association between new CAs and the extent of aortic valve calcification. Although shorter MS was observed in patients with newonset LBBB compared with patients without new-onset LBBB $(7.4 \pm 2.8 \mathrm{~mm}$ vs. $8.3 \pm 2.5 \mathrm{~mm}, \mathrm{P}=0.02)$, the length was similar between patients with and without new PPM implantation $(7.9 \pm 3.1 \mathrm{~mm}$ vs. $7.9 \pm 2.7 \mathrm{~mm}, \mathrm{P}=0.92)$. In contrast, smaller $\triangle$ MSID was significantly associated with both new-onset LBBB $(1.8 \pm 3.1 \mathrm{~mm}$ vs. $3.1 \pm 3.2 \mathrm{~mm}, \mathrm{P}=0.002)$ and new PPM implantation $(1.5 \pm 3.4 \mathrm{~mm}$ vs. $2.8 \pm 3.1 \mathrm{~mm}$, $\mathrm{P}=0.007)$. Representative cases are shown in Figure 2.

\section{Predictors of Conduction Abnormalities}

Figure 3 shows the inverse relationship between MS length and $\triangle$ MSID and the likelihood of CAs. Patients in the lowest quartile of MS length $(\leq 6.3 \mathrm{~mm})$ and $\Delta \mathrm{MSID}(\leq 0.69 \mathrm{~mm})$ had the highest incidence of CAs. Table 2 shows the results of univariate logistic regression analysis of predictors of subsequent CAs after TAVR. In the univariate analysis, the odds ratio (OR) for new CAs was increased in patients with CKD (OR: 1.78; 95\% confidence interval [CI]: 1.06 to 2.98; $\mathrm{P}=0.03$ ), longer PR interval (OR: 1.02; 95\% CI: 1.01 to $1.03 ; \mathrm{P}<0.001$ ), shorter MS (OR: $0.88 ; 95 \% \mathrm{CI}$ : 0.80 to $0.97 ; \mathrm{P}=0.01)$, greater ID (OR: $1.15 ; 95 \% \mathrm{CI}: 1.01$ to 1.31 ; $\mathrm{P}=0.02$ ), and decreased $\triangle \mathrm{MSID}$ (OR: $0.84 ; 95 \% \mathrm{CI}: 0.76$ to $0.92 ; \mathrm{P}<0.001)$.

Multivariate logistic regression analysis for the preprocedural prediction model revealed PR interval (OR: 1.01; 95\% CI: 1.00 to $1.03 ; \mathrm{P}=0.006)$ and MS length (OR: 0.84 ; $95 \%$ CI: 0.73 to $0.97 ; \mathrm{P}=0.02$ ) as independent predictors of CAs after TAVR (Table 3). In the postprocedural prediction model, PR interval (OR: $1.02 ; 95 \%$ CI: 1.00 to 1.03 ; $\mathrm{P}=0.006$ ) and $\triangle$ MSID (OR: $0.77 ; 95 \% \mathrm{CI}: 0.67$ to 0.89 ; $\mathrm{P}<0.001)$ were independent predictors of CAs.

\section{Difference Between Types of Valve}

Baseline and procedural characteristics of the subgroups of patients with SAPIEN 3 and Evolut R valves are shown in the Supplementary Table 1 and Supplementary Table 2. Among all patients, $180(74 \%)$ received a SAPIEN 3 prosthesis and 62 patients $(26 \%)$ received a Evolut $\mathrm{R}$ prosthesis. In each subgroup, significantly smaller $\triangle$ MSID was apparent in patients with CAs $(2.0 \pm 3.2 \mathrm{~mm}$ vs. $3.5 \pm 2.8 \mathrm{~mm}$, $\mathrm{P}=0.002$ and $1.1 \pm 2.9 \mathrm{~mm}$ vs. $3.2 \pm 3.7 \mathrm{~mm}, \mathrm{P}=0.02$, respectively), while MS length did not reach significant difference between patients with and without CAs $(7.5 \pm 3.0 \mathrm{~mm}$ vs. $8.3 \pm 2.4 \mathrm{~mm}, \mathrm{P}=0.06$ and $7.5 \pm 2.6 \mathrm{~mm}$ vs. $8.7 \pm 2.5 \mathrm{~mm}, \mathrm{P}=0.08$, respectively). Similarly, prosthesis oversizing was not associated with CAs in the 2 subgroups. 


\begin{tabular}{|c|c|c|}
\hline & OR (95\% Cl) & $P$ value \\
\hline Age, years & $1.01(0.97-1.04)$ & 0.71 \\
\hline Male & $1.05(0.63-1.76)$ & 0.85 \\
\hline Body mass index, $\mathrm{kg} / \mathrm{m}^{2}$ & $1.03(0.98-1.07)$ & 0.25 \\
\hline Hypertension & $0.67(0.33-1.37)$ & 0.27 \\
\hline Diabetes mellitus & $1.05(0.61-1.82)$ & 0.86 \\
\hline Dyslipidemia & $1.18(0.71-1.96)$ & 0.53 \\
\hline CKD & $1.78(1.06-2.98)$ & 0.03 \\
\hline COPD & $1.15(0.59-2.24)$ & 0.68 \\
\hline Cerebrovascular disease & $0.64(0.30-1.37)$ & 0.25 \\
\hline Ischemic heart disease & $0.63(0.38-1.05)$ & 0.08 \\
\hline AF history & $1.38(0.80-2.38)$ & 0.24 \\
\hline PR interval, ms & $1.02(1.01-1.03)$ & $<0.001$ \\
\hline Presence of RBBB & $1.40(0.68-2.87)$ & 0.36 \\
\hline Presence of LBBB & - & - \\
\hline Duration of QRS, ms & $1.00(1.00-1.01)$ & 0.21 \\
\hline Logistic EuroSCORE & $1.00(0.98-1.02)$ & 0.98 \\
\hline \multicolumn{3}{|l|}{ Echocardiographic data } \\
\hline Mean aortic gradient, $\mathrm{mmHg}$ & $1.00(0.99-1.02)$ & 0.64 \\
\hline Aortic valve area, $\mathrm{cm}^{2}$ & $0.98(0.28-3.44)$ & 0.98 \\
\hline LVEF, \% & $0.59(0.07-5.07)$ & 0.63 \\
\hline $\mathrm{sPAP}, \mathrm{mmHg}$ & $1.00(0.98-1.03)$ & 0.76 \\
\hline \multicolumn{3}{|l|}{ CT data } \\
\hline Annulus area, $\mathrm{mm}^{2}$ & $1.00(1.00-1.00)$ & 0.30 \\
\hline MS length, mm & $0.88(0.80-0.97)$ & 0.01 \\
\hline Calcification in basal septum & $1.11(0.66-1.89)$ & 0.69 \\
\hline AV calcium score, per 100 & $1.02(1.00-1.04)$ & 0.09 \\
\hline MV calcium score, per 100 & $1.01(1.00-1.02)$ & 0.13 \\
\hline \multicolumn{3}{|l|}{ Type of valve } \\
\hline SAPIEN 3 & $0.72(0.40-1.28)$ & 0.26 \\
\hline Evolut $\mathrm{R}$ & $1.39(0.78-2.48)$ & 0.26 \\
\hline Procedure time, $\min$ & $1.00(0.99-1.01)$ & 0.94 \\
\hline Predilatation & $1.57(0.94-2.63)$ & 0.09 \\
\hline Postdilatation & $0.49(0.16-1.45)$ & 0.20 \\
\hline Implantation depth (mean), mm & $1.15(1.01-1.31)$ & 0.02 \\
\hline$\Delta \mathrm{MSID}, \mathrm{mm}$ & $0.84(0.76-0.92)$ & $<0.001$ \\
\hline
\end{tabular}

$\mathrm{Cl}$, confidence interval; OR, odds ratio. Other abbreviations as in Table 1.

\section{Prognostic Effect of Conduction Abnormalities}

At 3 years after TAVR, the incidence of MACE was $53.4 \%$ in patients with new CAs and $30.1 \%$ in patients without new CAs (Figure 4). The hazard ratio (HR) of MACE during the 3 years after TAVR was 2.10 (95\% CI: 1.26 to 3.57 ; $\mathrm{P}=0.004)$. In a subanalysis, new-onset $\mathrm{LBBB}$ and new PPM implantation were both related to increased MACE rates at 3 years (HR: $1.88 ; 95 \%$ CI: 1.13 to $3.13 ; \mathrm{P}=0.01$ and HR $1.90 ; 95 \% \mathrm{CI}: 1.07$ to $3.25 ; \mathrm{P}=0.03$, respectively) (Supplementary Figure 1). The Kaplan-Meier curves for each event included in the combined endpoint are shown in Supplementary Figures 2-4. CAs were associated with all-cause death (HR 2.07; 95\% CI: 1.07 to 4.13; $\mathrm{P}=0.03$ ), stroke (HR 3.08; 95\% CI: 1.16 to $9.62 ; \mathrm{P}=0.02$ ), and heart failure hospitalization (HR 2.17; 95\% CI: 1.11 to 4.41; $\mathrm{P}=0.02$ ) during the 3-year follow-up.

\begin{tabular}{|lcc|}
\hline \multicolumn{3}{|l|}{ Table 3. Multivariate Analyses for Prediction of New } \\
Conduction Abnormalities & \\
& OR (95\% Cl) & P value \\
Preprocedure & & \\
CKD & $1.83(0.89-3.75)$ & 0.10 \\
Ischemic heart disease & $0.79(0.39-1.60)$ & 0.51 \\
PR interval, ms & $1.01(1.00-1.03)$ & 0.006 \\
MS length, mm & $0.84(0.73-0.97)$ & 0.02 \\
AV calcium score, per 100 & $1.01(0.99-1.04)$ & 0.38 \\
Pre- and postprocedure & & \\
CKD & $1.74(0.82-3.71)$ & 0.15 \\
Ischemic heart disease & $0.84(0.40-1.77)$ & 0.65 \\
PR interval, ms & $1.02(1.00-1.03)$ & 0.006 \\
AV calcium score, per 100 & $1.01(0.98-1.04)$ & 0.46 \\
$\Delta$ MSID, mm & $0.77(0.67-0.89)$ & $<0.001$ \\
Predilatation & $1.98(0.92-4.30)$ & 0.08 \\
\hline
\end{tabular}

Abbreviations as in Table 1.

\section{Discussion}

The aim of the present study was to investigate predictors of new-onset LBBB and/or new PPM implantation specifically in patients undergoing TAVR with new-generation valves. The major findings were: (1) the rate of CAs following TAVR was $47 \%$ overall; (2) similar incidence of CAs was observed in patients with SAPIEN 3 or Evolut R valves; (3) $\triangle$ MSID was the strongest predictor of CAs with newgeneration valves; and (4) compared with patients with no CAs, the risk of adverse clinical events was increased in patients with new CAs.

\section{Possible Mechanisms of Conduction Abnormalities}

Previous studies have indicated that direct injury of the intraventricular conduction system during valve implantation is the possible mechanism of CAs.19,20 The atrioventricular (AV) conduction axis originates from the compact AV node and is located along the inferior edge of the MS. ${ }^{21,22}$ The axis gives rise to the left bundle branch along the crest of the muscular ventricular septum. Therefore, a direct injury during valve implantation is likely to provoke new-onset LBBB or high-degree AVB following TAVR.

\section{Incidence of Conduction Abnormalities}

The occurrence of new-onset CAs after TAVR has had varying incidence reported across studies. ${ }^{7-13}$ The incidence of new-onset LBBB has been more frequent when the selfexpandable CoreValve system (Medtronic) is used (18$65 \%$ ), compared with $4-30 \%$ reported with the use of the balloon-expandable Edwards SAPIEN/SAPIEN XT valve (Edwards Lifesciences). ${ }^{5}$ Consistently, the rate of PPM implantation has also been higher with the CoreValve system than with SAPIEN/SAPIEN XT valve (25-28\% vs. $5-7 \%)$. For the newer generation valves, several studies have indicated that the occurrence of new-onset CAs was higher with SAPIEN 3 implantation than with the SAPIEN XT. De Torres-Alba et al reported that both the incidence of new PPM implantation $(19.1 \%$ vs. $12.2 \%$, $\mathrm{P}=0.046)$ and new-onset $\mathrm{LBBB}(13.0 \%$ vs. $10.8 \%, \mathrm{P}=0.492)$ were higher for SAPIEN 3.8 Similarly, the SOURCE 3 Registry (SAPIEN Aortic Bioprosthesis European Outcome) also demonstrated a higher rate of new PPM 


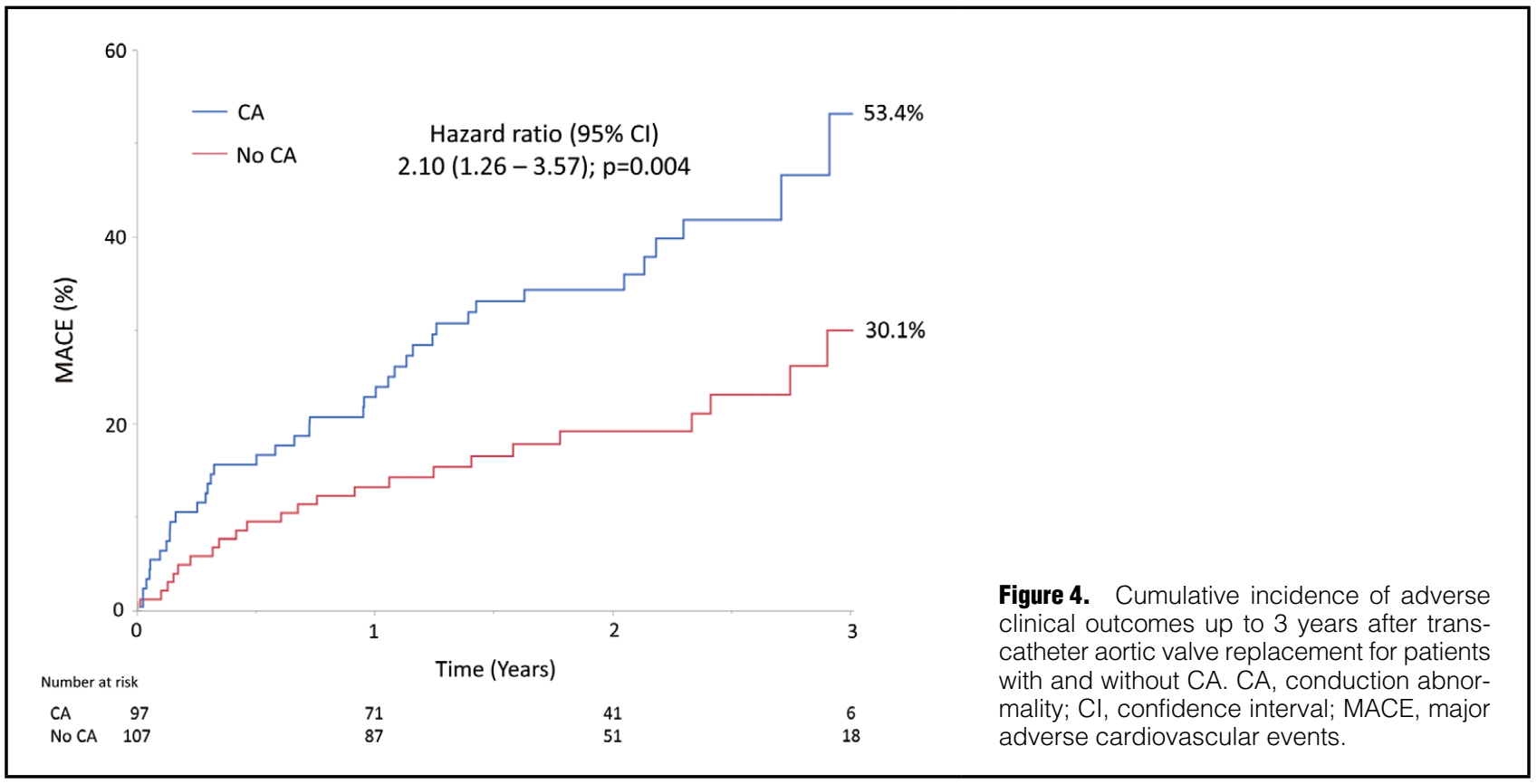

implantation for SAPIEN $3(12 \%$ vs. $6 \%) .{ }^{23}$ In contrast, CAs after TAVR with Evolut $\mathrm{R}$ are reported to be less frequent than with CoreValve (new-onset LBBB: $11.7 \%$ vs. $44.7 \%, \mathrm{P}<0.05$; new PPM implantation $10.9 \%$ vs. $21.6 \%$, $\mathrm{P}=0.01) .{ }^{24}$ It is noteworthy that our data showed similar rates of CAs between SAPIEN 3 and Evolut R. However, the results should be interpreted with caution because our study was not powered to compare these 2 types of valves. Non-significant increase in the rate of CAs was observed in patients with Evolut $\mathrm{R}$ as compared with patients with SAPIEN 3 (53\% vs. $45 \%, \mathrm{P}=0.26)$, suggesting that larger studies are warranted to confirm our findings.

Although the timing of PPM implantation and indications vary among institutions, the CAs rate in the present study $(47 \%)$ was similar to that in a recent study reported by Jørgensen et al, which suggested that new-onset LBBB and new PPM implantation occurred in $45 \%$ of patients undergoing TAVR with various types of valves. ${ }^{4}$

\section{Predictors of Conduction Abnormalities}

Identified risk factors for new-onset LBBB include selfexpandable valve, ID, and overexpansion of the native aortic annulus. ${ }^{\mathbf{2 0 , 2 5 , 2 6}}$ Similarly, the predictors of PPM implantation include the same factors but also baseline RBBB and first-degree AVB. ${ }^{11,27-30}$ Furthermore, Hamdan et al demonstrated that shorter MS and $\triangle$ MSID were related to new PPM implantation following TAVR in a registry including 73 self-expandable valve recipients $(6.5 \pm 2.6 \mathrm{~mm}$ vs. $9.3 \pm 2.9 \mathrm{~mm}, \mathrm{P}<0.001$ and $-1.2 \pm 4.2 \mathrm{~mm}$ vs. $3.7 \pm 4.3 \mathrm{~mm}$, $\mathrm{P}<0.001$, respectively). ${ }^{13}$ Likewise, Maeno et al studied a cohort of 240 SAPIEN 3 recipients and suggested a relationship between MS length or $\triangle$ MSID and the need for PPM implantation $(6.4 \pm 1.7 \mathrm{~mm}$ vs. $7.7 \pm 1.9 \mathrm{~mm}, \mathrm{P}<0.001$ and $0.6 \pm 2.9 \mathrm{~mm}$ vs. $-2.5 \pm 2.4 \mathrm{~mm}, \mathrm{P}<0.001$, respectively). ${ }^{12} \mathrm{In}$ contrast, Oestreich et al failed to identify an association of MS length or $\triangle$ MSID with new-onset LBBB or new PPM implantation $(7.9 \pm 2.0 \mathrm{~mm}$ vs. $7.2 \pm 2.0 \mathrm{~mm}, \mathrm{P}=0.20$ and $0.5 \pm 4.0 \mathrm{~mm}$ vs. $1.1 \pm 4.0 \mathrm{~mm}, \mathrm{P}=0.48$, respectively) in a series of 102 SAPIEN 3 recipients. ${ }^{31}$ These differences across studies may be partly explained by variations in the location of the MS itself relative to the plane of the visual basal ring. ${ }^{22}$ The MS is also known to vary in size, ${ }^{32,33}$ a variation recognizable using CT analysis, ${ }^{34}$ and there is variation in the rotation of the aortic root due to the underlying ventricular mass. ${ }^{35}$ Accordingly, discrepancies may be found among studies especially when the sample size is small. The present study included 242 TAVR patients with preprocedural MDCT data, which is the largest study to assess the periprocedural predictors of CAs, including MS length. Our study underlined that the clinically relevant measurement is not the height of the MS, but rather the relationship of the depth of the implanted valve relative to its inferior aspect. Interestingly, our study demonstrated that $\triangle \mathrm{MSID}$ was related to CAs with both new-generation balloon- and self-expandable valves.

Although prior studies have demonstrated that calcification of the left coronary cusp or the device-landing zone is predictive of PPM implantation after TAVR, ${ }^{36,37}$ we could not find a relationship between the aortic valve calcium score and CAs. In the present study, the spatial distribution of the calcification was not considered, which could be an explanation for the observed differences. Fujita et al revealed that the total calcium was not related to new PPM implantation after TAVR, but there was a strong correlation between an elevated level of left coronary cusp calcification and PPM implantation. ${ }^{37}$ Shifting the valvuloplasty balloon and the TAVR valve away from the left coronary cusp towards the right/noncoronary cusp region was considered a potential mechanism of injuring the conduction pathway.

\section{Clinical Outcomes of New-Onset LBBB and New PPM Implantation After TAVR}

Prior studies with more than 1 year of follow-up have failed to show an association between new PPM implantation after TAVR and all-cause death. However, those studies included patients with new-onset LBBB in the no PPM 
implantation group. Given that LBBB increases the risk of MACE, ${ }^{38,39}$ the inclusion of patients with LBBB in a comparator group might be why previous studies did not identify an association between new PPM implantation following TAVR and long-term adverse outcomes. Recently, Jørgensen et al reported that new bundle branch block and new PPM implantation were both associated with late all-cause death after TAVR. ${ }^{4}$ Our findings were consistent with these observations, as patients with newonset LBBB or new PPM implantation in our cohort had developed cardiovascular events 2 -fold at the 3-year follow-up.

\section{Study Limitations}

First, the decision to implant a PPM was ultimately at the discretion of the attending physician. The decision for choosing to implant a PPM may differ among physicians and even more widely among institutions. To account for the effect of such variations on the outcome parameter, we selected not just the PPM rate as the dependent variable but also LBBB, for which there is no physician- or institution-dependent variation. Second, a modest proportion of patients $(n=171)$ were excluded from initial enrollment, mostly due to the absence of analyzable CT images. Third, the presence of CAs was evaluated during the patient's admission, meaning that some patients might have been misclassified because of only transient LBBB.

\section{Conclusions}

$\triangle$ MSID was the most powerful predictor of CAs following TAVR with new-generation valves. New-onset CAs were associated with adverse clinical outcomes at 3 years. The procedural aspect of higher valve implantation, relative to MS length, may mitigate the occurrence of CAs following TAVR.

\section{Acknowledgments}

None.

\section{Disclosures}

K.M. has received a scholarship from the Uehara Memorial Foundation. The other authors have reported that they have no relationships to disclose.

\section{IRB Information}

The approval for this study was obtained from the France 2 study: 911262.

\section{References}

1. Reardon MJ, Van Mieghem NM, Popma JJ, Kleiman NS, Søndergaard L, Mumtaz M, et al. Surgical or transcatheter aorticvalve replacement in intermediate-risk patients. $N$ Engl $J$ Med 2017; 376: $1321-1331$.

2. Thyregod HG, Steinbrüchel DA, Ihlemann N, Nissen H, Kjeldsen $\mathrm{BJ}$, Petursson $\mathrm{P}$, et al. Transcatheter versus surgical aortic valve replacement in patients with severe aortic valve stenosis: 1-year results from the All-Comers NOTION randomized clinical trial. J Am Coll Cardiol 2015; 65: 2184-2194.

3. Smith CR, Leon MB, Mack MJ, Miller DC, Moses JW, Svensson LG, et al. Transcatheter versus surgical aortic-valve replacement in high-risk patients. $N$ Engl J Med 2011; 364: 2187-2198.

4. Jørgensen TH, De Backer O, Gerds TA, Bieliauskas G, Svendsen $\mathrm{JH}$, Sondergaard L. Mortality and heart failure hospitalization in patients with conduction abnormalities after transcatheter aortic valve replacement. JACC Cardiovasc Interv 2019; 12: 52-61.

5. Auffret V, Puri R, Urena M, Chamandi C, Rodriguez-Gabella T, Philippon F, et al. Conduction disturbances after transcatheter aortic valve replacement: Current status and future perspectives. Circulation 2017; 136: 1049-1069.

6. Mangieri A, Lanzillo G, Bertoldi L, Jabbour RJ, Regazzoli D, Ancona MB, et al. Predictors of advanced conduction disturbances requiring a late $(\geq 48 \mathrm{~h})$ permanent pacemaker following transcatheter aortic valve replacement. JACC Cardiovasc Interv 2018; 11: 1519-1526.

7. Husser O, Pellegrini C, Kessler T, Burgdorf C, Thaller H, Mayr $\mathrm{NP}$, et al. Predictors of permanent pacemaker implantations and new-onset conduction abnormalities with the SAPIEN 3 balloonexpandable transcatheter heart valve. JACC Cardiovasc Interv 2016; 9: 244-254.

8. De Torres-Alba F, Kaleschke G, Diller GP, Vormbrock J, Orwat $\mathrm{S}$, Radke R, et al. Changes in the pacemaker rate after transition from edwards SAPIEN XT to SAPIEN 3 transcatheter aortic valve implantation: The critical role of valve implantation height. JACC Cardiovasc Interv 2016; 9: 805-813.

9. Rodes-Cabau J, Urena M, Nombela-Franco L, Amat-Santos I, Kleiman N, Munoz-Garcia A, et al. Arrhythmic burden as determined by ambulatory continuous cardiac monitoring in patients with new-onset persistent left bundle branch block following transcatheter aortic valve replacement: The MARE study. JACC Cardiovasc Interv 2018; 11: 1495-1505.

10. Nazif TM, Dizon JM, Hahn RT, Xu K, Babaliaros V, Douglas PS, et al. Predictors and clinical outcomes of permanent pacemaker implantation after transcatheter aortic valve replacement: The PARTNER (Placement of AoRtic TraNscathetER Valves) trial and registry. JACC Cardiovasc Interv 2015; 8(1 Pt A): 60-69.

11. Siontis GC, Juni P, Pilgrim T, Stortecky S, Büllesfeld L, Meier B, et al. Predictors of permanent pacemaker implantation in patients with severe aortic stenosis undergoing TAVR: A meta-analysis. J Am Coll Cardiol 2014; 64: 129-140.

12. Maeno Y, Abramowitz Y, Kawamori H, Kazuno Y, Kubo S, Takahashi N, et al. A highly predictive risk model for pacemaker implantation after TAVR. JACC Cardiovasc Imaging 2017; 10(10 Pt A): $1139-1147$.

13. Hamdan A, Guetta V, Klempfner R, Konen E, Raanani E, Glikson M, et al. Inverse relationship between membranous septal length and the risk of atrioventricular block in patients undergoing transcatheter aortic valve implantation. JACC Cardiovasc Interv 2015; 8: $1218-1228$.

14. Miki T, Senoo K, Ohkura T, Kadoya Y, Ito N, Kuwabara K, et al. Importance of preoperative computed tomography assessment of the membranous septal anatomy in patients undergoing transcatheter aortic valve replacement with a balloon-expandable valve. Circ J 2020; 84: 269-276.

15. Surawicz B, Childers R, Deal BJ, Gettes LS, Bailey JJ, Gorgels $\mathrm{A}$, et al AHA/ACCF/HRS recommendations for the standardization and interpretation of the electrocardiogram: Part III: Intraventricular conduction disturbances: A Scientific Statement from the American Heart Association Electrocardiography and Arrhythmias Committee, Council on Clinical Cardiology; the American College of Cardiology Foundation; and the Heart Rhythm Society. Endorsed by the International Society for Computerized Electrocardiology. J Am Coll Cardiol 2009; 53: 976-981.

16. Mata-Mbemba D, Labani A, El Ghannudi S, Jeung MY, Ohlmann $\mathrm{P}$, Roy C, et al. 320-row CT transcatheter aortic valve replacement planning with a single reduced contrast media bolus injection. PLoS One 2018; 13: 0204145 .

17. Agatston AS, Janowitz WR, Hildner FJ, Zusmer NR, Viamonte M Jr, Detrano R. Quantification of coronary artery calcium using ultrafast computed tomography. J Am Coll Cardiol 1990; 15: $827-832$.

18. Maeno Y, Abramowitz Y, Yoon SH, Jilaihawi H, Raul S, Israr S, et al. Transcatheter aortic valve replacement with different valve types in elliptic aortic annuli. Circ J 2017; 81: 1036-1042.

19. Piazza N, Onuma Y, Jesserun E, Kint PP, Maugenest AM, Anderson RH, et al. Early and persistent intraventricular conduction abnormalities and requirements for pacemaking after percutaneous replacement of the aortic valve. JACC Cardiovasc Interv 2008; 1: 310-316.

20. Franzoni I, Latib A, Maisano F, Costopoulos C, Testa L, Figini $\mathrm{F}$, et al. Comparison of incidence and predictors of left bundle branch block after transcatheter aortic valve implantation using the CoreValve versus the Edwards valve. Am J Cardiol 2013; 112: 554-559.

21. Anderson RH, Boyett MR, Dobrzynski H, Moorman AF. The anatomy of the conduction system: Implications for the clinical cardiologist. J Cardiovasc Transl Res 2013; 6: 187-196. 
22. Tretter JT, Mori S, Saremi F, Chikkabyrappa S, Thomas K, Bu F, et al. Variations in rotation of the aortic root and membranous septum with implications for transcatheter valve implantation. Heart 2018; 104: 999-1005.

23. Wendler O, Schymik G, Treede H, Baumgartner H, Dumonteil N, Ihlberg L, et al. SOURCE 3 Registry: Design and 30-day results of the European postapproval registry of the latest generation of the SAPIEN 3 transcatheter heart valve. Circulation 2017; 135: $1123-1132$

24. Ojeda S, Hidalgo F, Romero M, Mazuelos F, Suárez de Lezo J, Martín E, et al. Impact of the repositionable Evolut R CoreValve system on the need for a permanent pacemaker after transcatheter aortic valve implantation in patients with severe aortic stenosis. Catheter Cardiovasc Interv 2020; 95: 783-790.

25. Katsanos S, van Rosendael P, Kamperidis V, van der Kley F, Joyce E, Debonnaire P, et al. Insights into new-onset rhythm conduction disorders detected by multi-detector row computed tomography after transcatheter aortic valve implantation. $\mathrm{Am} \mathrm{J}$ Cardiol 2014; 114: 1556-1561.

26. Urena M, Mok M, Serra V, Dumont E, Nombela-Franco L, DeLarochellière R, et al. Predictive factors and long-term clinical consequences of persistent left bundle branch block following transcatheter aortic valve implantation with a balloon-expandable valve. J Am Coll Cardiol 2012; 60: 1743-1752.

27. López-Aguilera J, Segura Saint-Gerons JM, Mazuelos Bellido F, Suárez de Lezo Herreros de Tejada J, Pineda SO, Pan ÁlvarezOssorio M, et al. Effect of new-onset left bundle branch block after transcatheter aortic valve implantation (CoreValve) on mortality, frequency of re-hospitalization, and need for pacemaker. $\mathrm{Am} J$ Cardiol 2016; 118: 1380-1385.

28. Kim WJ, Ko YG, Han S, Kim YH, Dy TC, Posas FE, et al. Predictors of permanent pacemaker insertion following transcatheter aortic valve replacement with the CoreValve revalving system based on computed tomography analysis: An Asian multicenter registry study. J Invasive Cardiol 2015; 27: 334-340.

29. Schroeter T, Linke A, Haensig M, Merk DR, Borger MA, Mohr FW, et al. Predictors of permanent pacemaker implantation after Medtronic CoreValve bioprosthesis implantation. Europace 2012; 14: $1759-1763$

30. Akin I, Kische S, Paranskaya L, Schneider H, Rehders TC, Trautwein U, et al. Predictive factors for pacemaker requirement after transcatheter aortic valve implantation. BMC Cardiovasc Disord 2012; 12: 87.

31. Oestreich BA, Mbai M, Gurevich S, Nijjar PS, Adabag S, Bertog
$\mathrm{S}$, et al. Computed tomography (CT) assessment of the membranous septal anatomy prior to transcatheter aortic valve replacement (TAVR) with the balloon-expandable SAPIEN 3 valve. Cardiovasc Revasc Med 2018; 19(5 Pt B): 626-631.

32. Icten $\mathrm{N}$, Tetik $\mathrm{S}$. The membranous portion of the interventricular septum in neonates. An anatomic study in neonatal cadavers. Surg Radiol Ana 1996; 18: 97-101.

33. Teofilovski-Parapid G, Baptista CA, DiDio LJ, Vaughan C. The membranous portion of the interventricular septum and its relationship with the aortic valve in humans. Surg Radiol Anat 1991; 13: $23-28$

34. Saremi F, Hassani C, Sanchez-Quintana D. Septal atrioventricular junction region: Comprehensive imaging in adults. Radiographics 2016; 36: 1966-1986.

35. Saremi F, Cen S, Tayari N, Alizadeh H, Emami A, Lin L, et al. A correlative study of aortic valve rotation angle and thoracic aortic sizes using ECG gated CT angiography. Eur J Radiol 2017; 89: $60-66$.

36. Latsios G, Gerckens U, Buellesfeld L, Mueller R, John D, Yuecel $\mathrm{S}$, et al. "Device landing zone" calcification, assessed by MSCT, as a predictive factor for pacemaker implantation after TAVI. Catheter Cardiovasc Interv 2010; 76: 431 - 439.

37. Fujita B, Kütting M, Seiffert M, Scholtz S, Egron S, Prashovikj $\mathrm{E}$, et al. Calcium distribution patterns of the aortic valve as a risk factor for the need of permanent pacemaker implantation after transcatheter aortic valve implantation. Eur Heart J Cardiovasc Imaging 2016; 17: 1385-1393.

38. Regueiro A, Abdul-Jawad Altisent O, Del Trigo M, CampeloParada F, Puri R, Urena M, et al. Impact of new-onset left bundle branch block and periprocedural permanent pacemaker implantation on clinical outcomes in patients undergoing transcatheter aortic valve replacement: A systematic review and meta-analysis. Circ Cardiovasc Interv 2016; 9: e003635.

39. Nazif TM, Chen S, George I, Dizon JM, Hahn RT, Crowley A, et al. New-onset left bundle branch block after transcatheter aortic valve replacement is associated with adverse long-term clinical outcomes in intermediate-risk patients: An analysis from the PARTNER II trial. Eur Heart J 2019; 40: 2218-2227.

\section{Supplementary Files}

Please find supplementary file(s):

http://dx.doi.org/10.1253/circj.CJ-20-0257 